\title{
Placental Barrier to Coagulation Factors: Its Relevance to the Coagulation Defect at Birth and to Haemorrhage in the Newborn
}

\author{
J. F. CADE,* M.B., M.R.A.C.P. ; J. HIRSH, $†$ M.D., M.R.A.C.P. ; M. MARTIN $\ddagger$
}

British Medical fournal, 1969, 2, 281-283

\begin{abstract}
Summary : The placental barrier to coagulation factors $\checkmark$ was assessed by measuring their levels in maternal venous and neonatal umbilical arterial and venous blood and was found to be largely complete. Detailed coagulation assessments in a large number of term and premature neonates showed that term neonates had a mild coagulation deficiency at birth. Premature neonates had a more definite deficiency, which became more severe with increasing prematurity. Mortality in low birth weight premature infants was associated with a severe coagulation deficiency, and was frequently due to cerebral haemorrhage. It is suggested that the coagulation system of low birth weight infants should be assessed to enable prophylactic treatment of those with a severe deficiency.
\end{abstract}

\section{Introduction}

Pregnancy is associated with a hypercoagulable state, which becomes most pronounced at term (Alexander et al., 1956; Fresh et al., 1956 ; Kasper et al., 1964 ; Talbert and Langdell, 1964; Johnson and Greenwalt, 1965; Gilliland, 1966; Markarian et al., 1967). The neonate, on the other hand, generally has a mild coagulation deficiency at birth (Aballi and De Lamerens, 1962 ; Oski and Naiman, 1966). It seems most likely that the maternal-neonatal difference in levels of coagulation factors is due $t s$ a placental barrier, but the completeness of this barrier is uncertain.

During the first few days of life the coagulation defect becomes accentuated; this phenomenon, which is often referred to as the physiological dip, is thought to be due to a combination of vitamin-K deficiency and hepatic immaturity (Aballi and De Lamerens, 1962 ; Hardisty and Ingram, 1965 ; Oski and Naiman, 1966). Though usually of little clinical importance, the early dip in coagulation factors could contribute to haemorrhagic problems if it aggravates an already appreciable coagulation defect. Haemorrhage is a common cause of mortality in premature neonates. These infants may have a pronounced coagulation deficiency at birth (Breton et al., 1960 ; Aballi and De Lamerens, 1962), but the incidence is uncertain, the severity variable, and the nature of the deficiency poorly documented. Furthermore, it is not known whether the coagulation status of the neonate at term is modified in any way by placental passage of maternal clotting factors.

In the present study the contribution of maternal factors to the coagulation status of the neonate was investigated by comparing the levels of a range of coagulation factors in a group of neonates and their mothers. A detailed coagulation assessment was performed in both term and premature neonates and the results were correlated with gestational age, birth weight, and the incidence of cerebral haemorrhage.

* Cardiovascular Registrar.

† Second Assistant, University of Melbourne Department of Medicins.

$\ddagger$ Medical Technologist, University of Melbourne Department of Medicine.

St. Vincent's Hospital, Melbourne.

Present address: N.H. and M.R.C. Medical Postgraduate Research Scholar, University of Melbourne Department of Medicine and Respiratory Unit, Royal Melbourne Hospital, Melbourne.

\section{Methods}

Blood for coagulation studies was obtained from 66 term and 35 premature neonates of between 26 and 37 weeks' gestation. Mixed cord blood from the term infants was taken in the labour ward as soon as possible after the completion of the second stage of labour by dripping $2.7 \mathrm{ml}$. of blood into a plastic tube containing $0.3 \mathrm{ml}$. of $3.8 \%$ sodium citrate. Some of the samples from premature infants were obtained in the same manner, while others were obtained within a few hours of birth from an indwelling catheter which had been passed via an umbilical artery into the aorta for use in routine fluid administration and blood sampling.

Neonatal-maternal comparisons were made on blood taken from 10 normal infants and their mothers. A segment of umbilical cord isolated between clamps was obtained immediately after completion of the second stage of labour. Then 3-ml. samples of blood were taken through a 20-gauge needle into a plastic syringe containing $0.3 \mathrm{ml}$. of $3.8 \%$ sodium citrate. The blood was taken from one umbilical artery, the umbilical vein, the second umbilical artery, and a maternal antecubital vein in that order. Platelet-poor plasma was prepared by centrifugation at $2,500 \mathrm{~g}$. for 10 minutes at room temperature and this was stored at $-20^{\circ} \mathrm{C}$. Coagulation tests were usually performed on the same day and always within three days of sample collection.

Coagulation Tests.-The following tests were used by inethods previously described (Hirsh et al., 1967): prothrombin time (P.T.), a commercial thromboplastin (Diagen) being used, kaolin partial thromboplastin (K.P.T.T.), factor V assay with artificial factor-V-deficient plasma, assay of factors VII and $\mathrm{X}$ complex, factor $\mathrm{X}$ assay with Russell's viper venom, factor II assay, factor VIII assay, and plasma fibrinogen estimation.

Classification of Severity of Coagulation Defect.-The coagulation inpairment has. been arbitrarily defined as mild if the prothrombin time was greater than normal but less than 23 seconds (greater than $30 \%$ ) or the kaolin partial thromboplastin time was greater than normal but less than 85 seconds ; moderate if the prothrombin time was between 23 and 33 seconds (30 and $15 \%$ ) or the kaolin partial thromboplastin time was between 85 and 110 seconds ; and severe if the prothrombin time was greater than 33 seconds (less than $15 \%$ ) or the kaolin partial thromboplastin time was greater than 110 seconds. When the two sets fell into different categories the classification reported has been that of the more severe defect.

\section{Results}

The analysis of results of coagulation tests performed on samples taken from the three umbilical vessels and from the mother are summarized in Table I. There was no significant difference in any of the tests between the samples raken from the two umbilical arteries, nor was there any difference between the umbilical venous and mean arterial values. On the other hand, a highly significant difference was found between the maternal and umbilical venous values for all tests except factors $\mathrm{V}$ and VIII assays. In addition, there was a lack of significant correlation between the materral and umbilical venous values to any test except factors II and $\mathrm{V}$ assays. A significant differ- 
ence was foumd in the levels of factors V, VII, and X between umbilical venous and mixed cord blood.

\begin{tabular}{|c|c|c|c|c|c|c|c|}
\hline Test & & $\mathrm{A} 1-\mathrm{A} 2$ & & $A-V$ & & V-C & $V-M$ \\
\hline $\begin{array}{l}\text { P.T. } \\
\text { (seconds) }\end{array}$ & $\left\{\begin{array}{l}\bar{x} \\
S_{\bar{d}} \\
r\end{array}\right.$ & $\begin{array}{c}20 \cdot 0 \quad 20 \\
0 \cdot 44 \\
\text { NS }\end{array}$ & & $\begin{array}{c}20 \cdot 0 \quad 19 \cdot 7 \\
0 \cdot 36 \\
\text { NS }\end{array}$ & & $\begin{array}{c}19 \cdot 7{ }^{1 \cdot 13^{17 \cdot 5}} \\
\text { NS }\end{array}$ & $\begin{array}{c}19 \cdot 7.15 \cdot 6 \\
0.96 \\
<0.002 \\
0.56\end{array}$ \\
\hline $\begin{array}{l}\text { K.P.T.T. } \\
\text { (seconds) }\end{array}$ & $\left\{\begin{array}{l}\overline{\mathrm{x}} \\
\mathrm{S}_{\overline{\mathrm{d}}} \\
\mathrm{r}\end{array}\right.$ & $\begin{array}{l}71 \\
1 \cdot 74 \\
\text { NS }\end{array}$ & 67 & $\begin{array}{c}70 \\
1.59 \\
\text { NS }\end{array}$ & 66 & ${ }_{\text {NS }}^{66}{ }^{71}$ & $\begin{array}{c}66.78 \\
3.79 \\
<0.01 \\
0.03\end{array}$ \\
\hline $\operatorname{II}_{(\%)}$ & $\left\{\begin{array}{l}\bar{x} \\
S_{\dot{d}} \\
P \\
r\end{array}\right.$ & $\begin{array}{l}32 \\
1 \cdot 70 \\
\text { NS }\end{array}$ & 34 & ${ }^{33}{ }^{5 \cdot 84}{ }^{3}$ & 32 & $\stackrel{32}{15 \cdot 3}{ }_{\text {NS }}^{60}$ & $\begin{array}{l}32 \\
10.4 \\
<0.01 \\
0.85^{*}\end{array}$ \\
\hline $\begin{array}{l}\mathrm{V} \\
(\%)\end{array}$ & $\left\{\begin{array}{l}\bar{x} \\
S \\
P \\
r\end{array}\right.$ & $\begin{array}{l}35 \\
1 \cdot 36 \\
\text { NS }\end{array}$ & 37 & ${ }_{\mathrm{NS}}^{36}{ }^{3}$ & 37 & $\begin{array}{l}37 \underset{12.6}{<0.001} \\
{ }^{3}\end{array}$ & $\begin{array}{l}37{ }^{3.72} 53 \\
(>0.25) \\
0.78^{*}\end{array}$ \\
\hline $\begin{array}{l}\text { VII } \\
\text { and } \\
\mathrm{X} \\
(\%)\end{array}$ & $\left\{\begin{array}{l}\overline{\mathrm{x}} \\
S_{\bar{d}} \\
\mathrm{P} \\
\mathrm{r}\end{array}\right.$ & $\begin{array}{l}21 \\
0 \cdot 77 \\
\text { NS }\end{array}$ & 22 & $\begin{array}{c}21 \text { 3.58 } \\
\text { NS }\end{array}$ & 26 & $\begin{array}{c}26 \\
7.10 \\
<0.001\end{array}$ & $\begin{array}{c}26.03 \\
<.03 \\
<0.001 \\
0.13\end{array}$ \\
\hline VIII & $\left\{\begin{array}{l}\overrightarrow{\mathrm{x}} \\
\mathbf{S} \\
\mathbf{P} \\
\mathrm{r}\end{array}\right.$ & $\stackrel{69}{14 \cdot 4} \underset{\text { NS }}{ }$ & 75 & $\begin{array}{l}72 \\
9 \cdot 22 \\
\text { NS }\end{array}$ & 55 & $\begin{array}{c}55 \\
17 \cdot 2 \\
\text { NS }\end{array}$ & $\begin{array}{l}55 \\
18.9 \\
(>0.05) \\
0.27\end{array}$ \\
\hline $\begin{array}{l}\mathrm{x} \\
(\%)\end{array}$ & $\left\{\begin{array}{l}\overline{\mathrm{x}} \\
\mathrm{S}_{\overline{\mathrm{A}}} \overline{\mathrm{A}} \\
\mathrm{P}\end{array}\right.$ & $\begin{array}{r}96 \\
\text { N.68 }\end{array}$ & 88 & ${ }_{\text {NS }}^{92}$ & 06 & ${\underset{17.7}{106}}_{<0.01} 55$ & $\begin{array}{c}106 \\
22 \cdot 6 \\
<0 \cdot 02 \\
0 \cdot 29\end{array}$ \\
\hline $\begin{array}{c}\text { Frbrin- } \\
\text { ogen } \\
(\mathrm{mg} . \\
100 \mathrm{ml} .)\end{array}$ & $\left\{\begin{array}{l}\overline{\bar{x}} \\
S_{\mathrm{d}}^{-} \\
P \\
r\end{array}\right.$ & $\begin{array}{c}243 \\
20 \cdot 6 \\
\text { NS }\end{array}$ & 249 & ${ }_{20 \cdot 6}^{246}{ }^{23}$ & 239 & ${ }_{\text {NS }}^{239}{ }^{193}$ & $\begin{array}{c}239 \quad 466 \\
11.5 \\
<0.001 \\
0.58\end{array}$ \\
\hline
\end{tabular}

NS $=$ Not significant if $P$ greater than 0.05

$\mathrm{A} 1-\mathrm{A} 2=$ Difference between the two umbilical arterial values. $\mathrm{A}-\mathrm{V}=\mathrm{Di}$ iference between the umbilical venous and mean arterial values. $V-C=D i f f e r e n c e$ between the umbilical venous and mixed cord values. $V-M=$ Difference and $c$ srrelation between umbilical and maternal venous values. $\overrightarrow{\mathbf{x}}=$ Mean values. Se $=$ Standard error of the mean difference. $\mathbf{r}=$ Correlation coefficient (*being significa $.2 t$ at less

TABLE II.-Coagulation Tests in Term Neonates

\begin{tabular}{|c|c|c|c|c|}
\hline Test & Mean & $\begin{array}{l}\text { Standard } \\
\text { Deviation }\end{array}$ & $\begin{array}{c}\text { No. of } \\
\text { Neonates }\end{array}$ & $\begin{array}{c}\text { Mean Adult } \\
\text { Value }\end{array}$ \\
\hline 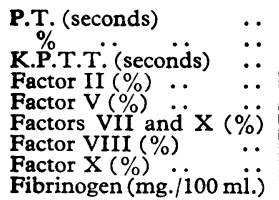 & $\begin{array}{l}17 \cdot 5 \\
78 \\
71 \\
60 \\
92 \\
56 \\
70 \\
55 \\
193\end{array}$ & $\begin{array}{l}3 \cdot 2 \\
21 \\
38 \\
41 \\
35 \\
56 \\
42 \\
102\end{array}$ & $\begin{array}{l}66 \\
66 \\
66 \\
12 \\
66 \\
66 \\
62 \\
63 \\
64\end{array}$ & $\begin{array}{r}15 \\
100 \\
50 \\
100 \\
100 \\
100 \\
100 \\
100 \\
290\end{array}$ \\
\hline
\end{tabular}

The coagulation tests in the term infants are summarized in Table II. All of these tests were markedly different from normal adult values except for the factor $\mathrm{V}$ level. The analysis of results of coagulation tests performed on the premature

Table III.-Coagulation Tests in Premature Neonates According to

\begin{tabular}{|c|c|c|c|c|}
\hline \multicolumn{5}{|c|}{ Gestational Age } \\
\hline Weeks: & 35 and 36 & 33 and 34 & $29-32$ & $<29$ \\
\hline 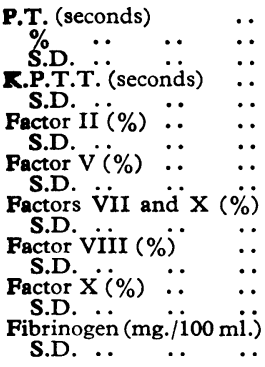 & $\begin{array}{l}16 \cdot 3 \\
88 \\
2 \cdot 3 \\
73 \\
19 \\
79 \\
37 \\
51 \\
20 \\
45 \\
26 \\
67 \\
97 \\
35 \\
26 \\
185 \\
72\end{array}$ & $\begin{array}{c}17 \cdot 9 \\
75 \\
4 \cdot 2 \\
100 \\
50 \\
46 \\
10 \\
49 \\
30 \\
37 \\
34 \\
21 \\
39 \\
12 \\
13 \\
179 \\
83\end{array}$ & $\begin{array}{l}21 \cdot 8 \\
40 \\
12 \cdot 8 \\
104^{*} \\
41 \\
53 \\
45 \\
58 \\
39 \\
36 \\
29 \\
46 \\
41 \\
45 \\
34 \\
267 \\
146\end{array}$ & $\begin{array}{c}35 \cdot 4^{*} \\
14 \\
21 \cdot 6 \\
147^{*} \\
42 \\
47 \\
30 \\
65 \\
48 \\
27 \\
18 \\
57 \\
61 \\
46 \\
31 \\
224 \\
187\end{array}$ \\
\hline
\end{tabular}

S.D. = Standard deviation.
Indicates significant difference $(P<0.05)$ in P.T. and K.P.T.T. compared with term neonates.

neonates are summarized in Table III in groups according to gestational age and in Table IV in groups according to birth weight. The most obvious abnormality of coagulation shown by newborn premature infants was prolongation of the prothrombin and the kaolin partial thromboplastin times with Increasing immaturity. A wide standard deviation was noted for both of these tests, especially among the more immature infants. In general, the mean values of the individual factors, apart from fibrinogen, factor VIII, and factor X, showed small and variable decreases with immaturity. The lack of a clearly progressive decrease in the levels of fibrinogen, factor VIII, and factor $X$ is not readily explained. Essentially similar results were obtained when the findings were analysed in terms of either gestational age or birth weight.

TABLE IV.-Coagulation Tests in Premature Neonates According to Birth Weight
\begin{tabular}{r|c|c|c|c} 
Birth Weight (g.): & $2,001-2,500$ & $1,501-2,000$ & $1,001-1,500$ & $<1,000$ \\
\hline P.T. (seconds) & 16.6 & $17 \cdot 3$ & $26 \cdot 6^{*}$ & $37 \cdot 0$
\end{tabular}

\begin{tabular}{|c|c|c|c|c|}
\hline$T$ (seconds) & & $17 \cdot 3$ & $26 \cdot 6^{*}$ & \\
\hline $\begin{array}{l}\text { P.1. (seconas) } \\
\%\end{array}$ & $\begin{array}{l}16 \cdot 6 \\
86\end{array}$ & $79 \cdot 3$ & 21 & 13 \\
\hline S.D. ... & 2.7 & 3.2 & $17 \cdot 3$ & 23.5 \\
\hline K.P.T.T. (seconds) & $77^{\circ}$ & 113 & $117^{*}$ & $132^{*}$ \\
\hline S.D. . . & 17 & 50 & 46 & 41 \\
\hline Factor II (\%) $\ldots$ & 99 & 70 & 47 & 13 \\
\hline S.D. & 49 & & 32 & 12 \\
\hline Factor V(\%) $\quad$.. & $\begin{array}{l}66 \\
38\end{array}$ & $\begin{array}{l}67 \\
22\end{array}$ & $\begin{array}{l}64 \\
41\end{array}$ & $\begin{array}{l}26 \\
17\end{array}$ \\
\hline Factors Vil and $\mathrm{x}(\%$ & 48 & 37 & 42 & 10 \\
\hline S.D. & 28 & 36 & 26 & 2 \\
\hline Factor VIII (\%) & $\begin{array}{l}21 \\
26\end{array}$ & $\begin{array}{l}44 \\
43\end{array}$ & $\begin{array}{l}50 \\
57\end{array}$ & $\begin{array}{l}45 \\
42\end{array}$ \\
\hline Factor $\mathrm{x}(\%) \quad \cdots$ & $\begin{array}{l}26 \\
22\end{array}$ & 29 & 39 & 46 \\
\hline S.D. ㅡ $\ddot{1} 00$ & $\begin{array}{r}19 \\
202\end{array}$ & $\begin{array}{r}30 \\
233\end{array}$ & $\begin{array}{r}33 \\
215\end{array}$ & $\begin{array}{r}39 \\
294\end{array}$ \\
\hline S.D. .. . . & 34 & 133 & 109 & 226 \\
\hline
\end{tabular}

S.D. = Standard deviation. erm neonates.

TABLE V.-Correlation of Coagulation Status with Clinical Course in Low Birth Weight Premature Neonates

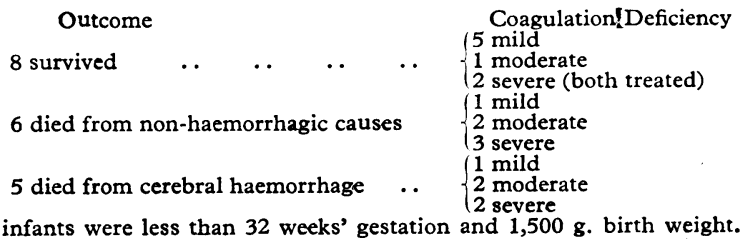

The correlation of coagulation status with the incidence of cerebral haemorrhage in the 19 premature neonates of less than $1,500 \mathrm{~g}$. birth weight and 32 weeks' gestation is shown in Table V. Eleven of the 19 babies died, five from cerebral haemorrhage and six from non-haemorrhagic causes, mainly prematurity or respiratory insufficiency. Nine of these 11 infants had moderate or severe coagulation impairment, and there appeared to be no difference in the coagulation status between those dying from haemorrhagic and non-haemorrhagic complications. Nevertheless, of the eight infants who survived, five had only mild coagulation impairment while there was one with moderate and two with severe deficiency. Both of the infants with severe deficiency who survived had replacement therapy with either fresh blood or fresh frozen plasma.

\section{Discussion}

The absence of any significant difference in coagulation tests performed on umbilical venous and arterial samples indicates that there is a placental barrier to coagulation factors. That this barrier is largely complete to factors VII and X and to fibrinogen is suggested by the large difference and the lack of correlation between neonatal and maternal values for these three factors. The significant correlation found between maternal and neonatal factor II and factor $\mathrm{V}$ levels may reflect the influence of a genetic control of these factors, or it may be a chance finding. The lack of correlation between neonatal and maternal values for factor VIII suggests that a major hereditary component is unlikely for this factor and is consistent with findings previously reported by Preston (1964) and by Kerr et al. (1966).

Variations were noted for some coagulation tests between samples obtained from umbilical venous and from mixed cord blood, and it would appear that mixed umbilical cord blood is not an ideal sample on which to perform detailed coagulation studies. Variability in methods of sampling may have been responsible for some of the differences in values obtained for 
coagulation factors in reported series (Johnson and Greenwalt, 1965).

The results of coagulation tests in the term neonates were similar to those reported by other writers (Aballi and De Lamerens, 1962; Oski and Naiman, 1966). Whether assessed on gestational age or birth weight, increasing prematurity was accompanied by further impairment of coagulation, particularly in factors V and VII and X complex. One of the most striking aspects of the coagulation status of newborn premature infants was the wide individual variation, so that some had values similar to those of term neonates, whereas others showed varying degrees of coagulation impairment which was sometimes severe. It would seem likely that this wide variation reflects different degrees of hepatic immaturity and not the influence of placental passage of maternal clotting factors.

It has usually been considered that cerebral haemorrhage occurring in low birth weight infants in the first few days of life is primarily due to hypoxic capillary damage. Nevertheless, it seems likely from our results and those reported by Gray et al. (1968) that a severe coagulation deficiency could be a major contributing factor. Thus using the Thrombotest Gray et al. (1968) reported a relationship between cerebral haemorrhage and a coagulation deficiency in low birth weight infants. The results of our detailed coagulation studies have also shown a marked difference in the coagulation status between low birth weight infants who survived and those who died; however, only one-half of the deaths were due to cerebral haemorrhage. This is probably because the coagulation defect is only one manifestation of immaturity and is therefore associated with other complications of marked prematurity. Nevertheless, the coagulation defect was sometimes severe enough to cause haemorrhage in its own right and of ten severe enough to aggravate bleeding produced by trauma or hypoxic capillary damage. A causal relationship between cerebral haemorrhage and a coagulation defect is further supported by the observation that the maximum incidence of cerebral haemorrhage occurs at about the same time as the maximum dip in coagulation factors.

Cerebral haemorrhage is a common cause of mortality in premature infants. Infants at high risk may be detected if screening tests such as the prothrombin and partial thromboplastin times were included in the early assessment of very low birth weight infants. The risk of cerebral haemorrhage might then be significantly reduced if infants shown to have a severe coagulation deficiency were treated prophylactically. Since the coagulation deficiency of prematurity is relatively unresponsive to vitamin $\mathrm{K}$ (Oski and Naiman, 1966), correction of the defect is most readily achieved by administration of small amounts of fresh frozen plasma.

These investigations would not have been possible without the help and co-operation of the medical and nursing staff of $\mathrm{St}$. Vincent's Maternity, the Royal Women's, and the Queen Victoria Hospitals. In particular we would like to thank Dr. W, H. Kitchen and Professor E. C. Wood for their encouragement, and Miss J. Pike for technical assistance. One of us (M. M.) is supported by a grant from the Australian National Heart Foundation. Details of results of individual coagulation tests are obtainable, on request, from Dr. J. Hirsh, to whom all correspondence should be addressed.

\section{REFERENCES}

Aballi, A. J., and De Lamerens, S. (1962). Pediatric Clinics of North America, 9, 785.

Alexander, B., Meyers, L., Kenny, J., Goldstein, R., Gurewich, V., and Grinspoon, L. (1956). New England fournal of Medicine, 254, 358 .

Breton, A., Goudemand, M., Hutin, A., Caudrelier, J.-R, and Gaudier, B. (1960). Archives Françaises dé Pédiatrie, 17, 143.

Fresh, J. W., Ferguson, J. H., and Lewis, J. H. (1956). Obstetrics and Gynecology, 7, 117 .

Gilliland, M. J.' (1966). Minnesota Medicine, 49, 1597.

Gray, O. P., Ackerman, A., and Fraser, A. J. (1968). Lancet, 1, 545.

Hardisty, R. M., and Ingram, G. I. C. (1965). Bleeding Disorders. Oxford, Blackwell.

Hirsh, J., Buchanan, J. G., de Gruchy, G. C., and Baikie, A. G. (1967). Lancet, 1, 418.

Johnson, S. A., and Greenwalt, T. J. (1965). Coagulation and Transfusion in Clinical Medicine. Boston, Little Brown.

Kasper, C. K., Hoag, M. S., Aggeler, P. M., and Stone, S. (1964). Obstetrics and Gynecology, 24, 242.

Kerr, C. B., Preston, A. E., Barr, A., and Biggs, R. (1966). British fournal of Haematology, $12,212$.

Markarian, M., Lindley, A., Jackson, J. J., and Bannon, A. (1967). Thrombosis et Diathesis Haemorrhagica" (Stuttgart), 17, 585.

Oski, F. A., and Naiman, J. L. (1966). Haematologic Problems in the Newborn. Philadelphia, Saunders.

Preston, A. E. (1964). British fournal of Haematology, $10,110$.

Talbert, L. M., and Langdell, R. D. (1964). American fournal of $\mathrm{Ob}$ stetrics and Gynecology, 90, 44.

\title{
Familial Plasma Lecithin:Cholesterol Acyltransferase Deficiency
}

\author{
BENGT HAMNSTRÖM,* M.D.; EGIL GJONE, $†$ M.D. ; KAARE R. NORUM, $\ddagger$ M.D.
}

Summary : A woman with familial plasma lecithin : $\checkmark$ cholesterol acyltransferase (L.C.A.T.) deficiency showed, like the other reported cases, obvious corneal opacity, proteinuria, and moderate anaemia with a slight haemolytic component. In the plasma the concentrations of free cholesterol, triglycerides, and lecithin were high, and those of esterified cholesterol, lysolecithin, and alphalipoprotein were low. L.C.A.T. activity in plasma was $10 \%$ of normal. The heparin-induced lipolytic activity in plasma was reduced. The erythrocyte lipid pattern was abnormal and showed the same pattern as earlier described in L.C.A.T. deficiency.

The patient's brother also probably suffered from the disease and died in uraemia. These are the fourth and fifth known patients with L.C.A.T. deficiency, the first one reported in a male, and the first one with a fatal outcome.

\section{Introduction}

The first three cases of plasma lecithin: cholesterol acyltransferase deficiency (L.C.A.T.) (plasma cholesterol ester deficiency) were reported from Norway (Norum and Gjone, 1967a, 1967b ; Gjone and Norum, 1968a, 1968b). The clinical features include proteinuria, normochromic anaemia with a haemolytic component, corneal opacity (Gjone and Bergaust, 1969), and turbid or milky plasma. Concentrations of plasma total cholesterol, triglycerides, and phospholipids were raised in the two oldest patients, the percentage of esterified cholesterol was very low, and the concentration of lysolecithin distinctly reduced in all cases. As determined by paper electrophoresis, precipitation

* Medical Department, Centrallasarettet, Karlstad, Sweden.

† Medical Department A, Rikshospitalet, University Hospital, Osło, Norway.

$\ddagger$ Institute of Clinical Biochemistry, Rikshospitalet, University of Oslo, Norway. 